\title{
Aplikasi Pengontrolan Kelembaban Tanah pada Smart Garden Menggunakan Sensor Soil Moisture
}

\author{
Faridah \\ Jurusan Teknik Elektro, Fakultas Teknik, Universitas Islam Makassar, \\ JI. Perintis Kemerdekaan km.9 No. 29 Makassar, Indonesia 90245 \\ e-mail: faridah.dty@uim-makassar.ac.id
}

\begin{abstract}
Abstrak
Persoalan penstabilan kelembaban tanah dapat ditangani dengan merancang sebuah aplikasi pengontrolan kelembaban tanah yang berfungsi untuk memberikan informasi kondisi kelembaban tanah dalam kurun waktu tertentu dalam bentuk perintah untuk melakukan penyiraman dan berhenti menyiram. Tujuan penelitian ini adalah melakukan simulasi sensing pada Aplikasi Pengontrolan Kelembaban Tanah Pada Smart Garden menggunakan sensor soil moisture. Penelitian ini merupakan penelitian eksperimen perancangan alat untuk meningkatkan kualitas dan sistem kerja alat. Tahap penelitian ini meliputi persiapan, rancangan spesifikasi komponen dan rangkaian, perancangan rangkaian, pembuatan jalur pengawatan, pembuatan konstruksi rangka, perakitan dan langkah kerja. Hasil penelitian menunjukkan bahwa alat akan berfungsi atau tidak, jika sensor mendeteksi bahwa tanah dalam keadaan kering atau hasil pengukuran pada sensor di bawah 50\%, maka sensor akan merespon dan mengirimkan sinyal ke microkontroler untuk mengaktifkan relay sehingga pompa akan menyala secara ototmatis. Jika alat tidak berfungsi, maka kita dapat melakukan secara manual degan melakukan pengontrolan melalui aplikasi smartphone. Namun pada saat tanah mencapai tingkat kelembaban tanah di atas $50 \%$ dari hasil penyiraman baik itu yang di lakukan oleh alat atau dari hujan yang di deteksi oleh sensor soil moisture, maka alat akan berhenti secara ototmatis. Alat akan kembali berfungsi saat tanah kembali kering, sehingga dapat mengontrol kelembaban tanah. Alat ini di lengkapi dengan indikator dengan menggunakan lampu LED ketika alat berfungsi.
\end{abstract}

Kata kunci: Kelembapan Tanah, Smart Garden, Sensor Soil Moisture.

\begin{abstract}
The problem of stabilizing soil moisture can be addressed by designing a soil moisture control application that serves to provide information on soil moisture conditions within a certain time period in the form of an order to water and stop watering. The research aims to carry out a sensing simulation on Soil Moisture Control Application in Smart Garden using Soil Moisture Sensor. This research is an experimental research of tool design in order to improve the quality and working system of the tool. The results of this study indicate that the device will function or not If the sensor detects that the ground is dry or the measurement results are brought to $50 \%$, then the sensor will respond and send a signal to the microcontroller to activate the relay so that the pump will turn on automatically. If the device does not function then we can do it automatically manually by controlling it via a smartphone application. When the soil reaches a soil moisture level above $50 \%$ from the results of either watering done by the tool or from the rain detected by the soil mousture sensor then the tool will stop automatically and the tool will return to function when the soil returns dry, so that it can control soil moisture. This tool is equipped with indicators using LED lights when the tool is functioning.
\end{abstract}

Keywords: Soil Moisture, Soil Moisture Sensor.

\section{Pendahuluan}

Program pembangunan pertanian terutama pada bidang kecukupan dan ketahanan pangan yang telah lama dilaksanakan di Luwu hingga sekarang masih sangat 
memprihatinkan, oleh karena itu masih dibutuhkan perhatian lebih oleh pemerintah untuk meningkatkan pertanian di Luwu. Dibeberapa negara maju dalam bidang pertanian seperti Jepang Tailand dan sebagian kecil perkebunan intensif di Indonesia mulai mengembangkan teknologi SMART GARDEN, suatu konsep pengolahan perkebunan menggunakan smart teknologi dimana semua pekerjaan menggunakan teknologi. Informasi kondisi tanaman dan tingkat kelembaban tanah terkendali oleh system, sangat berbeda dengan yang digunakan oleh para petani tradisional.

Persoalan penstabilan kelembaban tanah dapat ditangani dengan merancang sebuah aplikasi pengontrolan kelembaban tanah yang berfungsi untuk memberikan informasi kondisi kelembaban tanah dalam kurun waktu tertentu dalam bentuk perintah untuk melakukan penyiraman dan berhenti menyiram. Ketika kondisi kelembaban tanah telah sesuai dengan yang diinginkan, secara otomatis alat akan berhenti bekerja sehingga dapat meningkatkan efektifitas waktu kerja dan efisiensi penggunaan air. Handoyo (2015) sebelumnya membahas mengenai alat penyiraman berbasis mikrokontroller ATMEGA 8535.

Dari wacana di atas maka dasar itulah kami menuangkan ide yang diperoleh dari hasil survei dan disiplin ilmu selama proses perkuliahan dan sekaligus mengaplikasikannya dengan merancang sebuah konsep "Aplikasi Pengontrolan Kelembaban Tanah Pada Smart Garden Menggunakan Sensor Soil Moisture". Penelitian ini bertujuan melakukan simulasi sensing pada Aplikasi Pengontrolan Kelembaban Tanah Pada Smart Garden menggunakan sensor soil moisture. Perbedaan dengan penelitian Handoyo (2015) adalah penelitian kali aplikasi ini dapat dihubungkan dengan LCD sebagai kontrol bekerjanya alat dengan baik.

\section{Metode}

Dalam melakukan penelitian ini, penulis menggunakan alat dan bahan Sensor Mousture, Relay 2 Channel, Node MCU V4 (esp8266), Kabel Jamper, Conektor, Casing, Adaptor, Pompa DC, LED. Penelitian ini merupakan penelitian eksperimen perancangan alat guna meningkatkan kualitas dan sistem kerja alat yaitu Rancang Bangun smart garden dengan pengontrolan kelembapan tanah menggunakan sensor soil moisture yang dapat digunakan pada perkebunan atau taman.

Metode penelitian yang digunakan adalah metode perancangan aplikasi dengan menggunakan sensor soil moisture. Pengumpulan data primer dalam perancangan ini adalah dengan melakukan pengamatan dan wawancara pada lembaga terkait dan data sekunder dengan melakukan data melalui studi pustaka sesuai dengan data yang dibutuhkan untuk perancangan alat. 


\section{Hasil Dan Pembahasan}

\section{Hasil}

Perangkat Keras (Hardware) yang telah berhasil dibuat dalam penelitian ini adalah alat pengontrolan kelembaban tanah dengan menggunakan sensor soil NodeMCU, Rangkaian catu daya, rangkaian sensor kelembaban ( soil moisture YL-69 ), rangkaian relay, rangkain LCD, seperti pada gambar 1 .

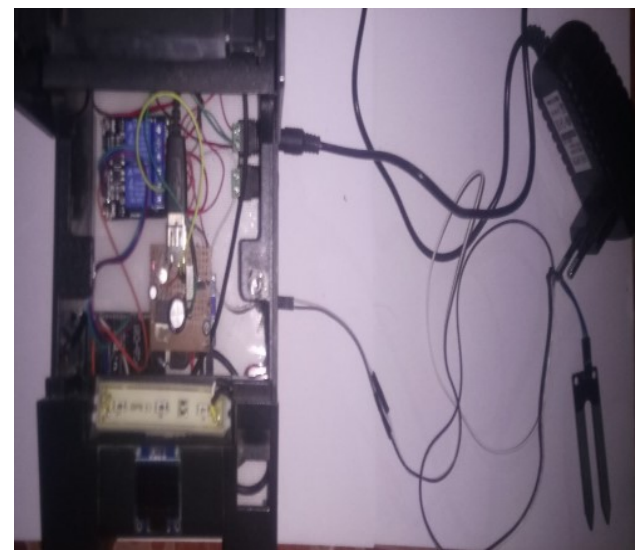

Gambar 1. Hasil pembuatan alat (hardware)

\section{Rangkaian NodeMCU}

Pada penelitian ini microcontroller yang digunakan adalah nodMCU V4 (ESP 8266). NodeMCU ini berfungsi untuk mengontrol sensor soil moisture dalam mengukur kelembaban tanah (Malik dan Juwana, 2009) dimana sensor soil moisture ini berfungsi berdasarkan tingkat kelembaban tanah dimana pada saat tanah dalam keadaan kering maka sensor soil moisture akan mengirimkan sinyal kepada node MCU untuk mengaktifkan pompa.

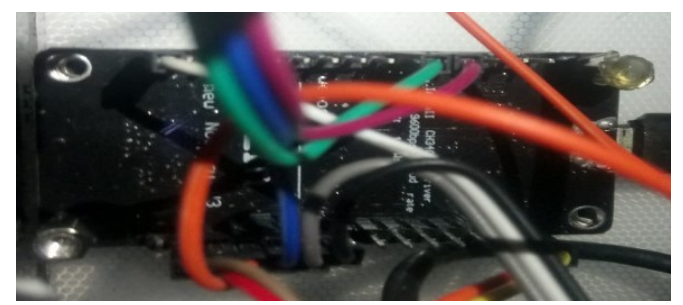

Gambar 2. Rangkaian nodeMCU

\section{Rangkaian catu Daya}

Rangkaian catu daya digunakan adaptor untuk mengubah tegangan listrik AC 220 volt menjadi tegangan listrik DC 12 Volt dan tegangan DC 12 volt menjadi tegangan DC 5 volt. Rangkaian catu daya pada penelitian ini digunakan untuk menyuplai tegangan pada nodeMCO dan relay (Wahyudin, 2007). Pada penelitian ini tegangan keluaran adaptor yang digunakan adalah sebesar 12 volt ke relay dan 5 volt ke nodeMCU. 


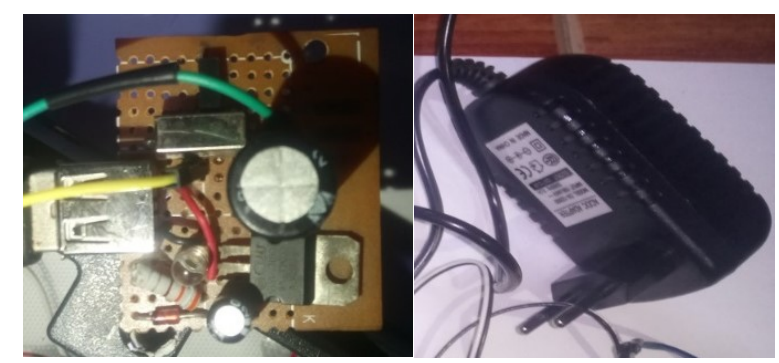

Gambar 3. catu daya penurun tegangan AC ke DC.

\section{Rangkaian sensor soil moisture}

Pada penelitian ini sensor soil moisture YL-69 digunakan untuk mendeteksi atau mengukur tingkat kelembaban tanah dalam bentuk persensentase (Setiawan, 2011). Di dalam sensor soil moisture YL-69 pin 1 di hubungkan ke sumber power 3V3. Di mana ia nantinya akan berfungsi untuk mengaktifkan sensor (Artanto, 2012). Ground (pin 4). la berfungsi sebagai sumber negative pada arus DC. Pin 2 ialah output dari sensor soil musture yang akan mengirimkan sinyal ke relay yang akan di proses terlebih dahulu melalui microkontroller.

\section{Layar LCD}

Berdasarkan hasil perancangan alat pengontrolan kelembaban tanah maka disimpulkan bahwa peggunaan Icd sangat efesien untuk memonitor alat untuk dapat mengetahui fungsi daripad alat dari layar Icd tersebut dapat di ketahui apakah lalat berfungsi atau tidak, bahkan degan alat tersebut kita dapat melakukan pengontrolan secara manual melalui aplikasi smartphone.

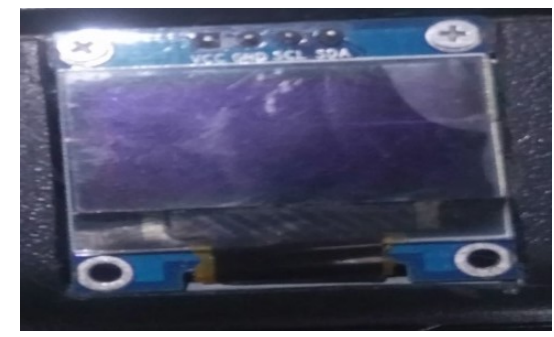

Gambar 4. gambar rangkaian LCD

\section{Pembahasan}

Mekanisme kerja rangkaian alat yang dirancang dalam penelitian ini adalah sebagai berikut. Rangkaian sensor akan mengukur kelembaban tanah yang selanjutnya akan mengirimkan sinyal kepada rangkaian NodeMCU untuk mengaktifkan pompa ketika tanah dalam keadaan kering. Rangkaian NodeMCU ini perlu disuplai oleh rangkaian catu daya. LCD memiliki fungsi sebagai pengontrol apakah alat bekerja dengan baik atau tidak. Cara kerja alat ini digambarkan dalam skema blok seperti pada gambar 5 . 


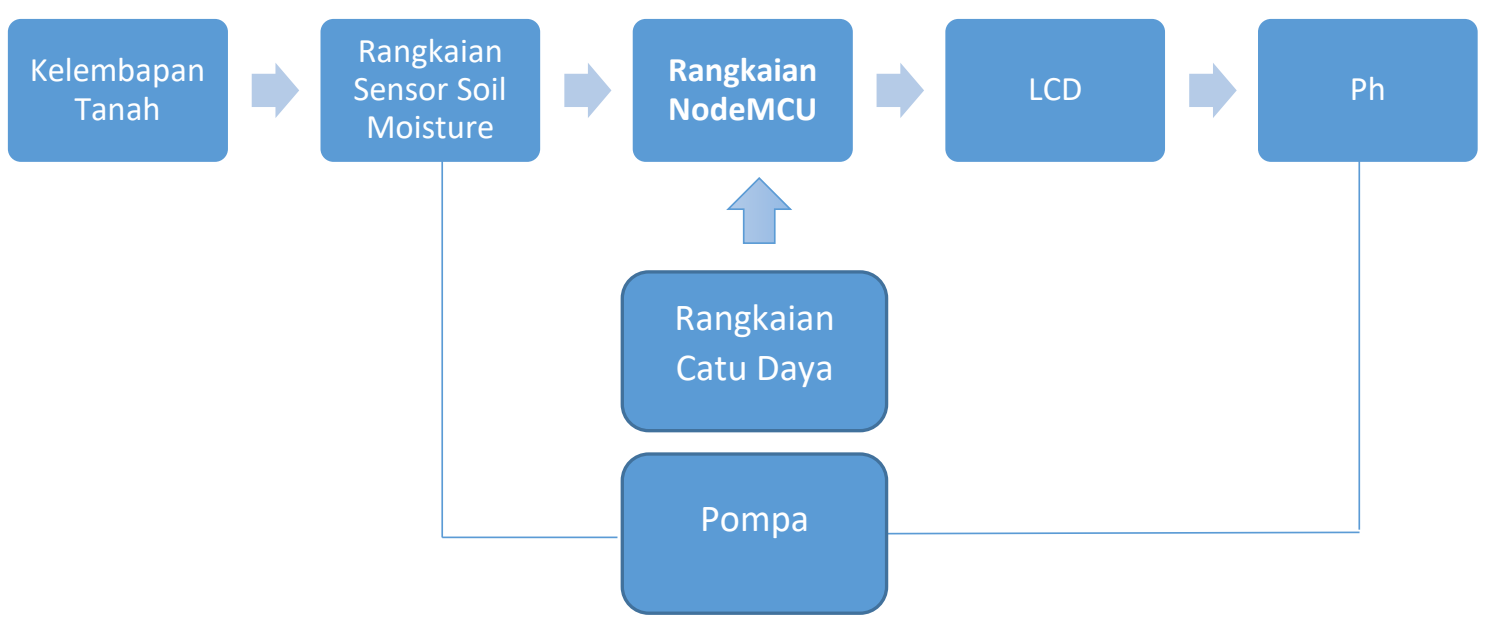

Gambar 5. Diagram Blok Sistem / Rangkaian Skematik

Pada bagian ini penulis melakukan pengujian terhadap rangkaian alat pengontrol mesin penyiram tanaman ototmatis berupa alat yang berfungsi berdasarkan kelembaban tanah dengan pengukur $\mathrm{PH}$ tanah yang telah di tentukan oleh alat, alat pendukung yaitu arduino nano. Adapun tujuan dari pengujian ini adalah :

a. Melaksanakan simulasi Sensing pada Aplikasi Pengontrolan Kelembaban Tanah Pada Smart Garden menggunakan sensor soil moisture.

b. Merancang Bangun Aplikasi Pengontrolan Kelembaban Tanah untuk meningkatkan produktifitas tanaman.

Setelah tahap perancangan selesai hingga terciptanya sebuah alat penyiram tanaman otomatis maka tahap selanjutnya adalah pengujian alat. Langkah ini di tempuh agar dapat di ketahui hasil darti system yang di buat dan melakukan perbaikan jika terdapat kesalahan.

Langkah langkah pengujian :

a. Hubungkan kabel power suplay rangkain

b. Tancapkan sensor soil mousture kedalam tanah

c. Aktifkan aplikasi pengontrolan di smartphone dan alat pengontrol kelembaban tanah dengan menekan saklar yang ada di bagian depan kesing alat penyiram tanaman.

d. LCD akan menyala untuk dapat di lihat persentase tingkat kelembaban, alat akan berfungsi atau tidak Jika sensor mendeteksi bahwa tanah dalam keadaan kering atau hasil pengukuran pada sensor dibawa 50\%, maka sensor akan merespon dan mengirimkan sinyal ke microkontroler untuk mengaktifkan relay sehingga pompa akan menyala secara ototmatis, Jika alat tidak berfungsi maka kita dapat melakukan secara manual degan melakukan pengontrolan melalui aplikasi 
smartphone . Namun pada saat tanah mencapai tingkat kelembaban tanah di atas $50 \%$ dari hasil penyiraman baik itu yang di lakukan oleh alat atau dari hujan yang di deteksi oleh sensor soil mousture maka alat akan berhenti secara ototmatis Dan alat akan kembali berfungsi saat tanah kembali kering. sehingga dapat mengontrol kelembaban tanah. Alat ini di lengkapi dengan indikator dengan menggunakan lampu LED ketika alat berfungsi.

\section{Kesimpulan}

Persoalan penstabilan kelembaban tanah dapat ditangani dengan merancang sebuah aplikasi pengontrolan kelembaban tanah yang berfungsi untuk memberikan informasi kondisi kelembaban tanah dalam kurun waktu tertentu dalam bentuk perintah untuk melakukan penyiraman dan berhenti menyiram. Penelitian ini telah merancang sebuah alat untuk mengontrol kelembaban tanah menggunakan sensor soil moisture.

Hasil penelitian menunjukkan bahwa alat akan berfungsi atau tidak, jika sensor mendeteksi bahwa tanah dalam keadaan kering atau hasil pengukuran pada sensor di bawah $50 \%$, maka sensor akan merespon dan mengirimkan sinyal ke microkontroler untuk mengaktifkan relay sehingga pompa akan menyala secara ototmatis. Jika alat tidak berfungsi, maka kita dapat melakukan secara manual degan melakukan pengontrolan melalui aplikasi smartphone. Namun pada saat tanah mencapai tingkat kelembaban tanah di atas $50 \%$ dari hasil penyiraman baik itu yang di lakukan oleh alat atau dari hujan yang dideteksi oleh sensor soil moisture, maka alat akan berhenti secara ototmatis. Alat akan kembali berfungsi saat tanah kembali kering, sehingga dapat mengontrol kelembaban tanah. Alat ini dilengkapi dengan indikator dengan menggunakan lampu LED ketika alat berfungsi.

\section{Daftar Pustaka}

Artanto, D. (2012). Interaksi arduino dan LabView. Jakarta: Elex Media Komputindo.

Handoyo, Y.T. (2015). Perancangan alat penyiram tanaman pintar berbasis mikrokontroller ATMEGA8535. Skripsi.Universitas Muhammadiyah Malang.

Malik, M.I. dan Juwana, M.U. (2009). Aneka proyek mikrokontroller PIC16F84/A. Jakarta: Elex Media Komputindo.

Setiawan, A. (2011). 20 aplkasi mikrokontroller ATMega 8535 dan ATMega 16. Yogyakarta: Andi.

Wahyuddin, D. (2007). Belajar mudah mikrokontroller AT8952 dengan basic menggunakan Baskom-805. Yogyakarta: Andi. 